\title{
Corneal Collagen Crosslinking for Keratectasia after Laser in situ Keratomileusis: A Review of the Literature
}

\author{
Leopoldo Spadea, Francesca Verboschi, Stefano Valente, Enzo Maria Vingolo
}

\begin{abstract}
Corneal ectasia is a serious vision-threatening complication of laser in situ keratomileusis (LASIK). It is associated with progressive corneal steepening, an increase in myopia and astigmatism, and decrease in uncorrected visual acuity. Before LASIK presence of risk factors (corneal thickness, refractive error, presence of clinical and subclinical corneal pathologies) should be studied so patients should be risk-stratified. Forme fruste keratoconus or marginal pellucid degeneration should be investigated before LASIK in order to inform the patients of the possibility to develop a corneal complication. Management of post-LASIK ectasia enlists crosslinking, INTACTS, contact lenses and, in the most serious cases, lamellar keratoplasty and corneal transplantation. Crosslinking is a technique to treat and even prevent post-LASIK corneal ectasia. LASIK is a technique that reduces the corneal strength and stability. Crosslinking increases the number of collagen interfibrillar covalent bonds, using ultraviolet $A$ and riboflavin. This result increases stability in corneal strength, reducing the risk to develop corneal ectasia (if performed simultaneously with LASIK) or it treats ectasia (if performed after LASIK keratectasia).
\end{abstract}

Keywords: Collagen crosslinking, Cornea, Keratectasia, LASIK.

How to cite this article: Spadea L, Verboschi F, Valente S, Vingolo EM. Corneal Collagen Crosslinking for Keratectasia after Laser in situ Keratomileusis: A Review of the Literature. J Kerat Ect Cor Dis 2013;2(3):113-120.

Source of support: Nil

Conflict of interest: None

\section{INTRODUCTION}

Iatrogenic corneal ectasia after laser in situ keratomileusis (LASIK) is one of the most feared complications of refractive surgery. ${ }^{1}$ There are several parameters, such as high myopic corrections, thin corneas and residual corneal bed thickness less than $250 \mu \mathrm{m}$, which represent major risk factors for this condition. ${ }^{2}$ Although the actual incidence of ectasia is unknown, it has been estimated to be 0.04 to $0.6 \% .^{3-5}$ These cases can be managed with lamellar or penetrating keratoplasty; however, minimally invasive techniques are also indicated. These options include medication to reduce intraocular pressure (IOP) ${ }^{6}$ rigid gas-permeable contact lenses, intrastromal corneal ring segments (ICRSs), ${ }^{7-9}$ and corneal crosslinking with ultraviolet A radiation and riboflavin treatment. ${ }^{10}$
Collagen crosslinking increases the biomechanical strength of the human cornea by about $300 \%$ by the combined action of a photosensitizing substance (riboflavin) and ultraviolet A (UVA) light from a solid-state source. ${ }^{11}$ The treatment creates additional chemical bonds inside the anterior 200 to 300 microns of the corneal stroma by means of photopolymerization. There is minimal exposure to the surrounding structures of the eye. ${ }^{12-14}$ Collagen crosslinking increases the resistance to pepsin digestion by enhancing corneal anticollagenase activity and induces a thicker collagen fiber diameter. ${ }^{15}$ Confocal microscopy studies have also shown apoptosis of keratocytes in the anterior and intermediate stroma followed by a gradual keratocytes repopulation. ${ }^{16}$

The object of this review is to illustrate keratectasia after LASIK and its treatment by collagen corneal crosslinking.

\section{LASIK}

\section{Technique}

An important part of population suffers from myopia and astigmatism, conditions that reduce visual acuity if not corrected with glasses. Nowaday, the introduction of excimer laser allowed the resolution of refractive error by corneal surgical techniques (LASIK, PRK, etc.) ${ }^{17}$

LASIK involves the formation of lamellar corneal flap and the remodeling of the underlying stromal tissue. The patient undergoing LASIK surgery, is medicated with topical anesthetic (e.g. oxybuprocaine), topical antibiotic (e.g. ciprofloxacin) and topical anti-inflammatory drops (e.g. dexamethasone).$^{18}$ The patient is positioned on the bed, a microkeratome or a femtosecond LASIK flap creates a corneal flap, an excimer laser remodels the corneal stroma in order to reduce the refractive error and then the corneal flap is repositioned. Femtosecond LASIK, compared with microkeratome, seems to show a better refractive outcome; in fact, the use of microkeratome resulted in a greater aberration values than femtosecond laser. ${ }^{19,20}$

\section{Corneal Ectasia after LASIK}

Thin-flap LASIK was conceived to reduce the thickness of the flap and consequently preserving the cornea stroma. Thin-flap LASIK is related to the possibility to increase the ability to treat higher myopia, and the use of thin-flap suggests to reduce the incidence of post-LASIK ectasia. 
Post-LASIK ectasia is one of the most insidious complication and, in 2008, Randleman et al developed an ectasia risk score system, which analyzed five criteria. The criteria analyzed were: age of patients, spheric equivalent of refractive error, residual stromal bed thickness, corneal thickness and abnormal corneal topography. This score is a useful tool, with a sensitivity of $91 \%$ and specificity of $92 \% .{ }^{21}$ Comaish and Lawless investigated the pathophysiology of progressive post-LASIK keratectasia (PPLK), considering this complication, linked to dynamic and static fatigue effects evaluating also the possibility subclinical inflammation that can lead to an activation of metalloproteinases and collagenases, resulting in a modification collagen fibers. These proteolytic modifications are studied in different pathologies in particular in keratoconus that shares with PPLK several aspects. ${ }^{22}$ Though in post-LASIK ectasia Meghpara et al did not find any classic pathognomonic signs of keratoconus, like the Bowman layer disruption, but found the presence of thinning of collagen fibrils and decreased interfibrillar distance. ${ }^{23}$

A high amount of tissue removed by the refractive procedure was associated with greater corneal biomechanical destabilization, increased corneal steepening and a worse prognosis. $^{24}$

Recently, we referred that the incidence of postLASIK corneal ectasia was $0.57 \%$ and the onset was about 2.5 years from operation. The patients were classified according to Randleman Ectasia Risk Score System, evidencing that the most important risk factors were a high spherical refractive error and a reduced corneal stromal bed. ${ }^{25}$ Binder et al compared different studies that reported the incidence of corneal ectasia post-LASIK treatment. The incidence reported was between 0.01 and $0.9 \%$. The authors referred several papers that reported cases of post-LASIK ectasia in keratoconus or pellucid marginal degeneration where there was not a well documented preoperative and postoperative study of corneal thickness, making impossible to know the residual corneal thickness. This is very important because post-LASIK residual corneal thickness is the most important factor influencing the ectasia onset. ${ }^{26}$ Binder et al clearly explained that the clinical examination at slit lamp permits to recognize keratoconus. Corneal topography is a valid exam to find the presence of forme fruste keratoconus before LASIK, and it is really important because forme fruste keratoconus could develop a clinical evident keratoconus. LASIK should be avoided in patients who show the blue-spot that is connected to possibility to develop pellucid marginal degeneration. ${ }^{27}$

\section{Treatment of Keratectasia after LASIK}

Although several risk factors for keratectasia after LASIK have been identified and screening techniques continue to improve, post-LASIK keratectasia still occurs. ${ }^{27}$ Invasive treatment of keratectasia include lamellar or penetrating keratoplasty: Kucumen et al described four patients who developed corneal ectasia after LASIK and required penetrating keratoplasty (PKP) and they confirmed that PKP is successful in treating severe corneal ectasia after LASIK, but the treatment of the patient may last for the rest of his or her life owing to potential postoperative complications. ${ }^{28}$

However, after the introduction and successful use of deep anterior lamellar keratoplasty (DALK), PKP is no longer the best choice in these cases. Deep anterior lamellar keratoplasty has the advantages of being an extraocular procedure that treats abnormal stroma and leaves the healthy endothelial cells in place. ${ }^{29,30}$ Results in several studies ${ }^{31-33}$ indicate the visual outcomes after DALK are comparable to those after PKP in cases of keratoconus. In addition, recent studies ${ }^{34-36}$ report promising results of DALK in cases of iatrogenic ectasia.

There are also minimally invasive techniques. A case of transient post-LASIK keratectasia associated with a marked elevation of intraocular pressure (IOP), where the keratectasia subsided promptly after IOP normalization treated with an intravenous administration of mannitol, has previously been reported. ${ }^{37}$

The use of intrastromal corneal ring segments (Intacs) for post-LASIK ectasia has been previously reported with positive results. ${ }^{8,38-40}$ Pokroy et al have used implantation of Intacs post-LASIK in five patients. Although the Intacs incision passed through the LASIK flap and the vacuumcentering guide acted at the center of the flap, the flap was not disrupted in any case. They had no superficial corneal buttonholing as we were careful to dissect the entire length of the Intacs channel at least $370 \mu \mathrm{m}$ deep, no segment extrusion as the proximal end of the segment was implanted at least $1.0 \mathrm{~mm}$ in the channel. Ectatic corneas are thinner, less rigid and less symmetric than normal corneas, making buttonholing and segment extrusion more likely if the above precautions are not taken. ${ }^{40}$

Treatment of post-LASIK ectasia with crosslinking procedures has also shown promise..$^{10,41}$

\section{Crosslinking}

Corneal collagen crosslinking (CXL) is a relatively new technique used for the stabilization of ectatic disorders. ${ }^{42,43}$ The objective of this technique is the increase of corneal strength and stability by inducing cross links at the corneal stroma ${ }^{44}$ using riboflavin as a photosensitizer and UVA to increase the formation of intra- and interfibrillar covalent bonds by photosensitized oxidation. Today, CXL with deepithelialization is limited to eyes with a corneal thickness 
of at least $400 \mu \mathrm{m}$ due to concerns about the cytotoxic effect on the endothelium, crystalline lens and other intraocular tissues. $^{45}$

Corneal crosslinking is an outpatient procedure generally performed with topical anesthesia. The epithelial cell layer is first removed, often using a blunt spatula, in a $9.0 \mathrm{~mm}$ diameter under sterile conditions. Then a topical $0.1 \%$ riboflavin (vitamin $\mathrm{B}_{2}$ ) solution is applied every 3 to 5 minutes for 15 to 30 minutes to ensure that the corneal stroma is fully penetrated. A solid-state UVA light source with a wavelength of $370 \mathrm{~nm}$ (maximum absorption of riboflavin) and an irradiance of $3 \mathrm{~mW} / \mathrm{cm}^{2}$ is used to irradiate the central cornea. Following treatment, a soft bandage lens is applied and prescriptions given for oral pain medications, preservative-free tears, anti-inflammatory drops and antibiotic eye drops. Patients are recalled at 1 week postprocedure to evaluate re-epithelialization, with subsequent follow-up appointments to monitor status.

Riboflavin acts as a photosensitizer and has an absorption peak for UVA wavelength of approximately 370 microns. ${ }^{43}$ Riboflavin-saturated cornea exposed to UVA irradiation at this wavelength fluoresces and is excited into a triplet state with subsequent generation of singlet oxygen (mainly) and superoxide anion radicals. The reactive oxygen species leads to the formation of covalent bonds bridging amino acids of collagen fibrils by oxidative process dependent on the presence of $\mathrm{O}_{2}$ and enhanced by deuterium oxide. The increased bonding in the corneal stromal layer leads to an increased 'stiffness' of the cornea.

The first reports of clinical experience with this treatment for corneal melting appeared in $2000 .{ }^{46}$ In 2003 , a halt in the progression of the keratectasia has been highlighted after CXL in eyes with progressive keratoconus. ${ }^{43}$ The authors found a decrease in maximum keratometry readings and an improvement in visual acuity during the first postoperative years. This finding was confirmed in 2006 by Caporossi et $\mathrm{al}^{47}$ in a 3-month follow-up after CXL as well as in 2008 by Wittig-Silva et $\mathrm{al}^{48}$ and in 2009 by Koller et $\mathrm{al}^{49}$ in controlled prospective studies with a completed 1-year follow-up. Other applications of CXL include iatrogenic keratectasia in pellucid marginal degeneration, ${ }^{50}$ after LASIK and PRK ${ }^{51-53}$ and infectious keratitis. ${ }^{54}$ All these studies found CXL to be efficacious in stopping the progression of keratectasia.

\section{Crosslinking and Keratoconus}

Keratoconus is a slowly progressive, noninflammatory corneal dystrophy characterized by changes in corneal collagen structure and organization. ${ }^{55-57}$ A reduced number of collagen cross-links and a pepsin digestion higher than normal induce an overall structural weakness of the corneal tissue, resulting in a stiffness that is only $60 \%$ that of the normal cornea. ${ }^{58}$ Decreased mechanical corneal stability plays an important role in the progressive protrusion of the keratoconic cornea, resulting in mild to marked impairment of visual acuity owing to irregular astigmatism, progressive myopia, corneal thinning and central corneal scarring. ${ }^{59}$ Keratoconus does not involve only the anterior surface of the cornea and its thickness. Rather, it affects all anterior segment parameters. ${ }^{60}$

Currently, available treatments for keratoconus (rigid contact lens, lamellar keratoplasty, corneal rings) largely involve interventions which are done for tectonic, optical or refractive reasons. ${ }^{61}$ Unfortunately, none of these options treat the underlying cause of ectasia and, therefore, cannot stop the progression of keratoconus. In recent years, basic laboratory studies and subsequent clinical studies have demonstrated stiffening of the cornea with use of UVA light and riboflavin solution as a photosensitizer-initiated corneal collagen crosslinking with no loss in corneal transparency. Vinciguerra et al have demonstrated a significant decrease in total corneal volume and anterior chamber depth (ACD) 12 months after CXL. ${ }^{62}$ Crosslinking induces the creation of new bonds between the collagen fibers. ${ }^{11,42,43,63,64}$ The reduction of $\mathrm{ACD}$ at the cone apex matched the maximum reduction in elevation and the increased packing of collagen fibers, as demonstrated by Mencucci et al. ${ }^{65}$ The results of the Siena Eye Cross Study showed a long-term stability of keratoconus after crosslinking without relevant side effects on 44 eyes after 48 months of minimum follow-up: the uncorrected visual acuity and best spectacle-corrected visual acuity improvements were supported by clinical, topographic and wavefront modifications induced by the treatment. ${ }^{66}$ Mazzotta et al have studied ultrastructural stromal modifications after riboflavin-UVA-induced crosslinking of corneal collagen in 10 patients with progressive keratoconus and they have showed a reduction in anterior and intermediate stromal keratocytes followed by gradual repopulation confirmed directly in vivo in humans by HRT II-RCM confocal microscopy. ${ }^{14}$

Nowadays, CXL is limited to eyes with a corneal thickness of at least $400 \mu \mathrm{m}$ due to concerns about the cytotoxic effect on the endothelium, crystalline lens and other intraocular tissues. ${ }^{43,45}$ This threshold has limited its performance in eyes with advanced stages of corneal ectasia. Transepithelial CXL, ${ }^{67} \mathrm{CXL}$ with customized pachymetricguided epithelial debridement to preserve the epithelium in thinner corneal regions, ${ }^{68}$ and the concept of iatrogenic corneal swelling before CXL application ${ }^{69}$ have each been developed as alternative techniques for thin corneas with thinnest pachymetry values of less than $400 \mu \mathrm{m} .^{70}$ 


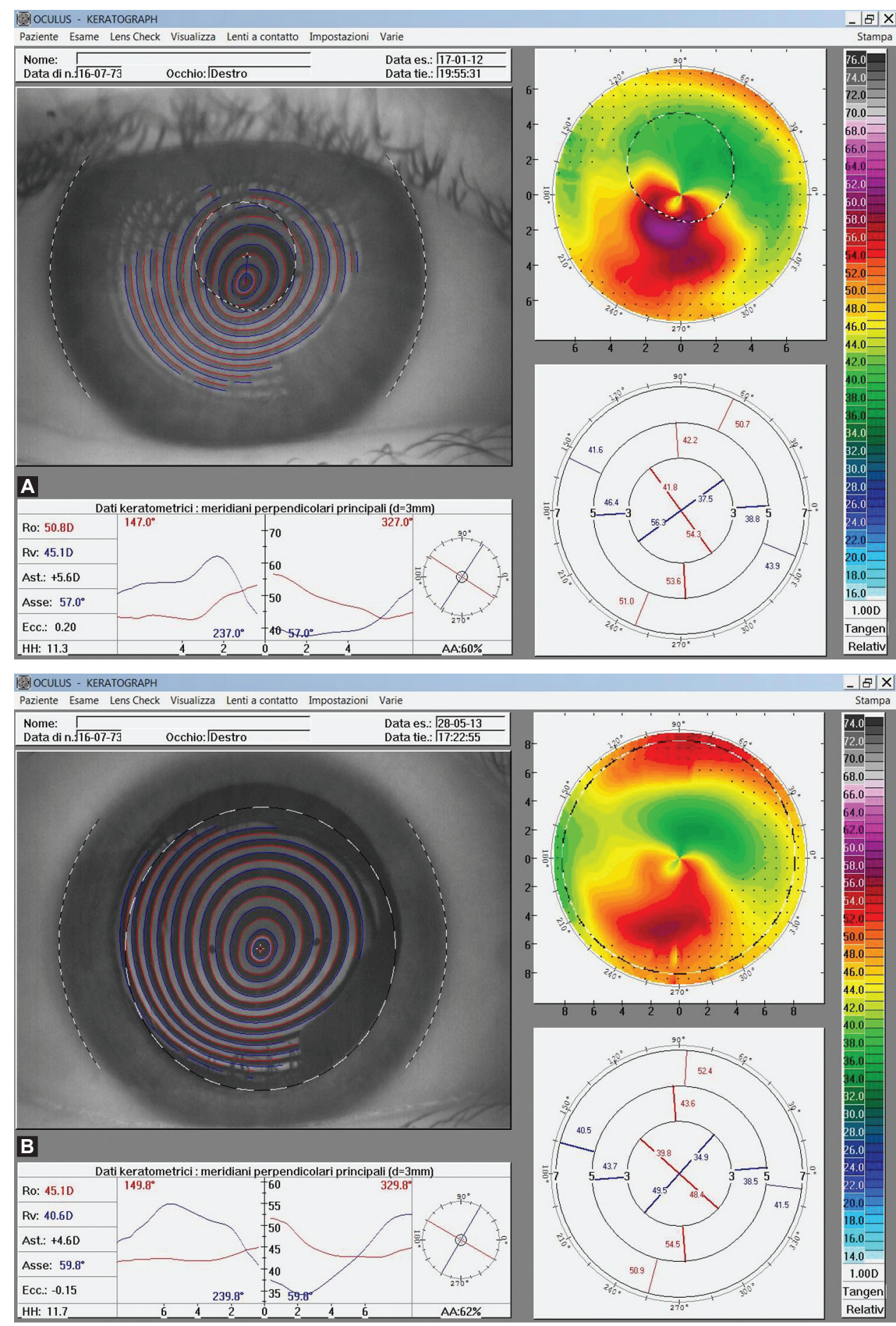

Figs 1 A and B: Right eye videokeratography maps before $(A)$ and 16 months after $(B)$ corneal collagen crosslinking for treatment of post-LASIK ectasia. The topographic pattern highlights the improved corneal profile obtained (keratograph - Oculus Optikgeräte $\mathrm{GmbH}$, Wetzlar, Germany — relative scale, tangential algorithm)

\section{Crosslinking and Keratectasia after LASIK}

Corneal ectasia is a serious vision-threatening complication of LASIK. ${ }^{71}$ It is associated with progressive corneal steepening, an increase in myopia and astigmatism, and decrease in uncorrected visual acuity. There are several parameters, such as high myopic corrections, thin corneas and residual corneal bed thickness less than $250 \mu \mathrm{m}$, which represent major risk factors for this condition. ${ }^{2}$ Clearly, prevention of induced keratectasia is the best strategy and special emphasis should be placed on recognizing corneas that are at risk before surgery. Reduction of corneal biomechanical strength seems to be an essential element in the chain of event leading to iatrogenic keratectasia after LASIK. The anterior stroma confers more biomechanical strength to the cornea than the posterior stroma, and it is the anterior stroma that is weakened by flap generation and 


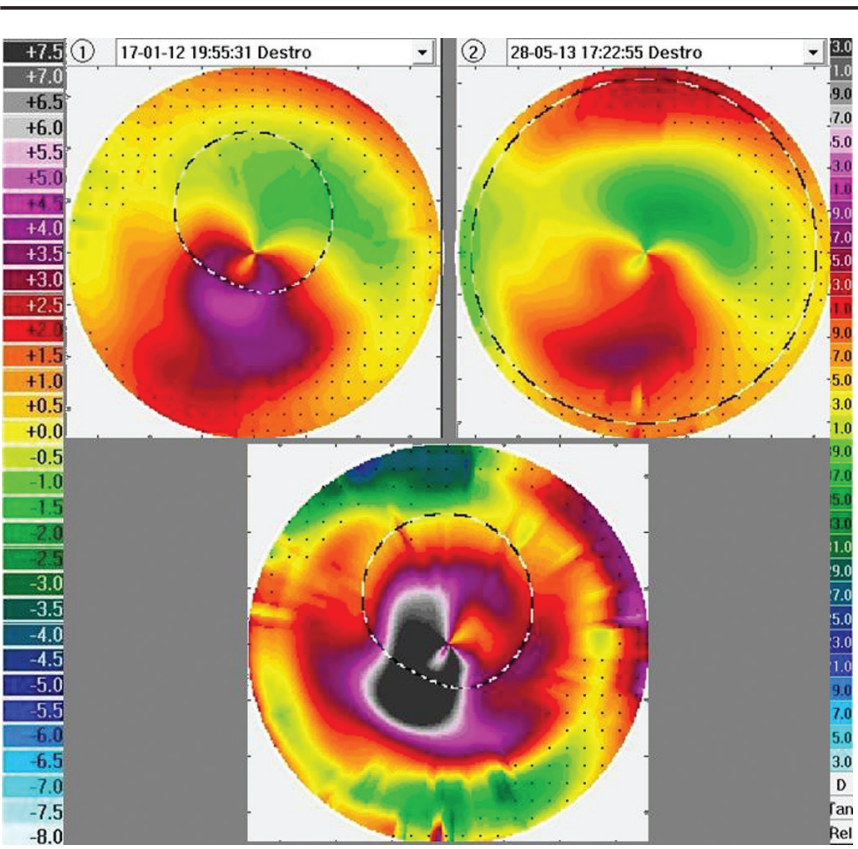

Fig. 2: Top left: videokeratography maps of a right eye before corneal collagen crosslinking for treatment of post-LASIK ectasia. Top right: 16 months after corneal collagen crosslinking. Middle bottom: difference videokeratography maps

tissue ablation in LASIK surgery. ${ }^{72}$ It would therefore be of great clinical value to have a tool to determine the individual biomechanical strength of a cornea preoperatively. Such a tool would enable us to detect corneas at risk preoperatively; unfortunately, this is not available. However, promising approaches are being studied. These include determination of corneal hysteresis using an ocular response analyzer or interferometric measurements. ${ }^{73,74}$

Several studies have reported on riboflavin-UVAinduced CXL as a treatment for postoperative LASIK ectasia (Figs $1 \mathrm{~A}$ and B). ${ }^{52}$ Kymionis et al studied a case in which patient underwent simultaneous topography guided PRK and CXL for the management of post-LASIK corneal ectasia. During the preoperative examination, the patient complained of deterioration of the visual acuity that could not been resolved with spectacles or contact lenses. ${ }^{75}$ Kohlhaas et al reported a case of iatrogenic keratectasia after LASIK that was successfully treated by crosslinking. ${ }^{51}$ In the study of Hafezi et al corneal crosslinking was performed in 10 patients with formerly undiagnosed forme fruste keratoconus or pellucid marginal corneal degeneration who had LASIK for myopic astigmatism and subsequently developed iatrogenic keratectasia. They showed that crosslinking induced by riboflavin and UVA arrested and/or partially reversed keratectasia over a postoperative followup of up to 25 months as demonstrated by preoperative and postoperative corneal topography and a reduction in maximum keratometric readings (Fig. 2). ${ }^{52}$ Kanellopoulos et $\mathrm{al}^{76}$ in a previous study proposed a two step procedure of corneal crosslinking followed by PRK with a 1 year interval. According to this study, documentation of the stability for at least 1 year is essential before proceeding with the laser treatment. This approach has several limitations. The stiffened crosslinked corneal tissue is partly removed by the consequential PRK procedure. There is no control over the efficacy of this approach, since the corneal ablation rate could be different in cross linked corneas as compared to virgin corneas and this could lead to unpredictable refractive results. Lastly, there is an increased possibility of post-PRK haze formation since it is known that, after $\mathrm{CXL}$, the anterior stromal is repopulated by new keratocytes after 6 months. ${ }^{10,77}$ In a prospective pilot interventional case series, Celik et al $^{78}$ performed simultaneous CXL and LASIK to prevent ectasia and found no occurrence of significant refractive change or side effects during the 1-year follow-up. The authors conclude that this procedure appears to be a promising modality for future applications to prevent corneal ectasia after LASIK treatment. Kymionis et al described a post-LASIK patient who developed diffuse lamellar keratitis (DLK) after corneal crosslinking treatment which was successfully treated with intensive topical corticosteroids. ${ }^{79}$ Several crosslinking factors, such as epithelium removal and UVA light, could trigger DLK. Epithelium removal has been related to epithelium-derived cytokines, such as interleukin-1, that stimulate keratocytes to produce chemokines which attract inflammatory cells. ${ }^{80}$

Moreover, prophylactic collagen crosslinking for highrisk LASIK cases $^{81}$ and combined to PRK to correct residual refractive error in patients previously submitted to lamellar keratoplasty for keratoconus ${ }^{82}$ was demonstrated to be a safe and effective adjunctive treatment for refractive regression and potential ectasia. In fact, prophylactic crosslinking may offer a significant benefit in patients with personal history of keratoconus and/or in the correction of high myopia and hyperopia.

\section{CONCLUSION}

As noted earlier, it is well known that LASIK reduces the biomechanical stability of the cornea by intersecting with structural lamellae in the anterior cornea and, of course, by removing some of the structural lamellae in lieu of ablation. Riboflavin-UVA corneal crosslinking increased the biomechanical and biochemical stability of the cornea and may thus be a therapeutic means to arrest or reverse the progression of LASIK-induced keratectasia. This application may be viewed as prophylactic customization of the biomechanical behavior of corneal collagen. 


\section{REFERENCES}

1. Seiler T, Koufala K, Richter G. Iatrogenic keratectasia after laser in situ keratomileusis. J Refract Surg 1998;14:312-317.

2. Kymionis G, Bouzoukis D, Diakonis V, et al. Long-term results of thin corneas after refractive laser surgery. Am J Ophthalmol 2007;144(2);181-185.

3. Binder PS. Analysis of ectasia after laser in situ keratomileusis: risk factors. J Cataract Refract Surg 2007;33:1530-1538.

4. Chen MC, Lee N, Bourla N, et al. Corneal biomechanical measurements before and after laser in situ keratomileusis. J Cataract Refract Surg 2008;34:1886-1891.

5. Kirwan C, O'Malley D, O'Keefe M. Corneal hysteresis and corneal resistance factor in keratectasia: finding using the Reichert ocular response analyzer. Ophtalmologica 2008;222:334-337.

6. Hiatt JA, Wachler BS, Grant C. Reversal of laser in situ keratomileusis-induced ectasia with intraocular pressure reduction. J Cataract Refract Surg 2005;31:1652-1655.

7. Alio J, Salem T, Artola A, et al. Intracorneal rings to correct corneal ectasia after laser in situ keratomileusis. J Cataract Refract Surg 2002;28:1568-1574.

8. Kymionis GD, Tsiklis NS, Pallikaris AI, et al. Long-term followup of Intacs for post-LASIK corneal ectasia. Ophthalmology 2006;113:1909-1917.

9. Siganos CS, Kymionis GD, Astyrakakis N, et al. Management of corneal ectasia after laser in situ keratomileusis with INTACS. J Refract Surg 2002;18:43-46.

10. Kymionis GD, Diakonis VF, Kalyvianaki M, et al. One-year follow-up of corneal confocal microscopy after corneal crosslinking in patients with post laser in situ keratomileusis ectasia and keratoconus. Am J Ophthalmol 2009;147:774-778.

11. Wollensak G, Spoerl E, Seiler T. Stress-strain measurements of human and porcine corneas after riboflavin-ultraviolet-A induced cross-linking. J Cataract Refract Surg 2003;29:1780-1785.

12. Kohlhaas M, Spoerl E, Schilde T, et al. Biomechanical evidence of the distribution of cross-links in corneas treated with riboflavin/ultraviolet A light. J Cataract Refract Surg 2006;32: 279-283.

13. Schilde T, Kohlhaas M, Spoerl E, et al. Enzymatic evidence of the depth dependence of stiffening on riboflavin/ UVA-treated corneas. Ophthalmology 2008;105:165-169.

14. Mazzotta C, Balestrazzi A, Traversi C, et al. Treatment of progressive keratoconus by riboflavin-UVA-induced crosslinking of corneal collagen ultrastructural analysis by Heidelberg retinal tomograph II in vivo confocal microscopy in humans. Cornea 2007;26:390-397.

15. Wollensak G, Spoerl E, Wilsch M, et al. Keratocyte apoptosis after corneal collagen cross-linking using riboflavin/UVA treatment. Cornea 2004;23:43-49.

16. Mazzotta C, Traversi C, Baiocchi S, et al. Conservative treatment of keratoconus by riboflavin-UVA-induced cross-linking of corneal collagen: qualitative investigation. Eur J Ophthalmol 2006;16:530-535.

17. Seiler T, McDonnell PJ. Excimer laser photorefractive keratectomy. Surv Ophthalmol 1995;40(2):89-118.

18. Lawless M, Hodge C. LASIK. Int Ophthalmol Clin 2013;53(1):111-128.

19. Chen S, Feng Y, Stojanovic A. IntraLase femtosecond laser versus mechanical microkeratomes in LASIK for myopia: a systematic review and meta-analysis. J Refract Surg 2012;28: $15-24$.
20. Zhang SH, Jin HY, Suo Y, et al. Femtosecond laser versus mechanical microkeratome laser in situ keratomileusis for myopia. Meta-analysis of randomised controlled trials. J Cataract Refract Surg 2011;37:2151-2159.

21. Randleman JB, Trattler WB, Stulting RD. Validation of the ectasia risk score system for preoperative laser in situ keratomileusis screening. Am J Ophthalmol 2008;145: 813-818.

22. Comaish IF, Lawless MA. Progressive post-LASIK keratectasia: biomechanical instability or chronic disease process? J Cataract Refract Surg 2002;28(12):2206-2213.

23. Meghpara B, Nakamura H, Macsai M, et al. Keratectasia after laser in situ keratomileusis: a histopathologic and immunohistochemical study. Arch Ophthalmol. 2008;126(12):1655-1663.

24. Brenner LF, Alió JL, Vega-Estrada A, et al. Clinical grading of post-LASIK ectasia related to visual limitation and predictive factors for vision loss. J Cataract Refract Surg 2012;38(10): 1817-1826.

25. Spadea L, Cantera E, Cortes M, Conocchia NE, Stewart CW. Corneal ectasia after myopic laser in situ keratomileusis: a longterm study. Clin Ophthalmol 2012;6:1801-1813.

26. Binder PS. Analysis of ectasia after laser in situ keratomileusis: risk factors. J Cataract Refract Surg 2007;33(9):1530-1538.

27. Binder PS, Lindstrom RL, Stulting RD, et al. Keratoconus and corneal ectasia after LASIK. J Cataract Refract Surg 2005;31:2035-2038.

28. Kucumen RB, Yenerel NM, Gorgun E, et al. Penetrating keratoplasty for corneal ectasia after laser in situ keratomileusis. Eur J Ophthalmol 2008;18:695-702.

29. Terry MA. The evolution of lamellar grafting techniques over twenty-five years. Cornea 2000;19:611-616.

30. Morris E, Kirwan JF, Sujatha S, et al. Corneal endothelial specular microscopy following deep lamellar keratoplasty with lyophilised tissue. Eye 1998;12:619-622.

31. Javadi MA, Feizi S, Yazdani S, et al. Deep anterior lamellar keratoplasty versus penetrating keratoplasty for keratoconus: a clinical trial. Cornea 2010;29:365-371.

32. Shimazaki J, Shimmura S, Ishioka M, et al. Randomized clinical trial of deep lamellar keratoplasty vs penetrating keratoplasty. Am J Ophthalmol 2002;134:159-165.

33. Sugita J, Kondo J. Deep lamellar keratoplasty with complete removal of pathological stroma for vision improvement. Br J Ophthalmol 1997;81:184-188.

34. Villarrubia A, Pérez-Santonja JJ, Palacín E, et al. Deep anterior lamellar keratoplasty in post-laser in situ keratomileusis keratectasia. J Cataract Refract Surg 2007;33:773-778.

35. McAllum PJ, Segev F, Herzig S, et al. Deep anterior lamellar keratoplasty for post-LASIK ectasia. Cornea 2007;26:507-511.

36. Chiou AGY, Bovet J, de Courten C. Management of corneal ectasia and cataract following photorefractive keratectomy. J Cataract Refract Surg 2006;32:679-680.

37. Toshino A, Uno T, Ohashi Y, et al. Transient keratectasia caused by intraocular pressure elevation after laser in situ keratomileusis. J Cataract Refract Surg 2005;31:202-204.

38. Siganos CS, Kymionis GD, Astyrakakis N, et al. Management of corneal ectasia after laser in situ keratomileusis with INTACS. J Refract Surg 2002;18:43-46.

39. Carrasquillo KG, Rand J, Talamo JH. Intacs for keratoconus and post-LASIK ectasia: mechanical versus femtosecond laserassisted channel creation. Cornea 2007;26:956-962. 
40. Pokroy R, Levinger S, Hirsh A. Single Intacs segment for postlaser in situ keratomileusis keratectasia. J Cataract Refract Surg 2004;30:1685-1695.

41. Kanellopoulos AJ. Post-LASIK ectasia. Ophthalmology 2007;114:1230.

42. Wollensak G, Spoerl E, Seiler T. Riboflavin/ultravioletA-induced collagen crosslinking for the treatment of keratoconus. Am J Ophthalmol 2003;135:620-627.

43. Wollensak G. Crosslinking treatment of progressive keratoconus: new hope. Curr Opin Ophthalmol 2006;17:356-360.

44. Spoerl E, Huhle M, Seiler T. Induction of cross-links in corneal tissue. Exp Eye Res 1998; 66:97-103.

45. Spoerl E, Mrochen M, Sliney D, et al. Safety of UVA riboflavin cross-linking of the cornea. Cornea 2007;26:385-389.

46. Schnitzler E, Spoerl E, Seiler T. Crosslinking of the corneal collagen by UV-radiation with riboflavin for the mode of treatment melting ulcera of the cornea, first results of four patients. Klin Monatsbl Augenheilkd 2000;217:190-193.

47. Caporossi A, Baiocchi S, Mazzotta C, et al. Parasurgical therapy for keratoconus by riboflavin-ultraviolet type A rays induced cross-linking of corneal collagen; preliminary refractive results in an Italian study. J Cataract Refract Surg 2006;32:837-845.

48. Wittig-Silva C, Whiting M, Lamoureux E, et al. A randomized controlled trial of corneal collagen cross-linking in progressive keratoconus: preliminary results. J Refract Surg 2008;24: S720-725.

49. Koller T, IseliHP, Hafezi F, et al. Scheimpflug imaging of corneas after collagen cross-linking. Cornea 2009;28:510-515.

50. Spadea L. Corneal collagen cross-linking with riboflavin and UVA irradiation in pellucid marginal degeneration. J Refract Surg 2010;26(5):375-377.

51. Kohlhaas M, Spoerl E, Speck A, et al. Eine neue Behandlung der Keratektasie nach LASIK durch Kollagenvernetzung mit Riboflavin/UVA-Licht. A new treatment of keratectasia after LASIK by using collagen with riboflavin/UVA light crosslinking. Klin Monatsbl Augenheilkd 2005;222:430-436.

52. Hafezi F, Kanellopoulos J, Wiltfang R, et al. Corneal collagen crosslinking with riboflavin and ultraviolet $\mathrm{A}$ to treat induced keratectasia after laser in situ keratomileusis. J Cataract Refract Surg 2007;33:2035-2040.

53. Spadea L. Collagen crosslinking for ectasia following PRK performed in excimer laser-assisted keratoplasty for keratoconus. Eur J Ophthalmol 2012;22:274-227.

54. Iseli HP, Thiel MA, Hafezi F, et al. Ultraviolet A/riboflavin corneal cross-linking for infectious keratitis associated with corneal melts. Cornea 2008;27:590-594.

55. Tuori AJ, Virtanen I, Aine E, et al. The immunohistochemical composition of corneal basement membrane in keratoconus. Curr Eye Res 1997;16:792-801.

56. Cheng EL, Maruyama I, SundarRaj N, et al. Expression of type XII collagen and hemidesmosome-associated proteins in keratoconus corneas. Curr Eye Res 2001;22:333-340.

57. Radner W, Zehetmayer M, Skorpik $\mathrm{CH}$, et al. Altered organization of collagen in apex of keratoconus corneas. Ophthalmic Res 1998;30:327-332.

58. Andreassen TT, Simonsen AH, Oxlund H. Biomechanical properties of keratoconus and normal corneas. Exp Eye Res 1980;31:435-441.

59. Rabinowitz YS. Keratoconus. Surv Ophthalmol 1998;42: 297-319.
60. Emre S, Doganay S, Yologlu S. Evaluation of anterior segment parameters in keratoconic eyes measured with the Pentacam system. J Cataract Refract Surg 2007;33:1708-1712.

61. Spadea L, Gizzi R, Evangelista Conocchia N, Urbano S. Optical pachimetry-guided customized excimer laser-assisted lamellar keratoplasty for the surgical treatment of keratoconus. J Cataract Refract Surg 2012;38:1559-1567.

62. Vinciguerra P, Albè E, Trazza S, et al. Refractive, topographic, tomographic, and aberrometric analysis of keratoconic eyes undergoing corneal cross-linking. Ophthalmology 2009;116:369-378.

63. Wollensak G, Spoerl E, Seiler T. Treatment of keratoconus by collagen crosslinking (in German). Ophthalmology 2003;100: 44-49.

64. Wollensak G, Redl B. Gel electrophoretic analysis of corneal collagen after photodynamic cross-linking treatment. Cornea 2008;27:353-356.

65. Mencucci R, Mazzotta C, Rossi F, et al. Riboflavin and ultraviolet A collagen crosslinking: in vivo thermographic analysis of the corneal surface. J Cataract Refract Surg 2007;33:1005-1008.

66. Caporossi A, Mazzotta C, Baiocchi S, et al. Long-term results of riboflavin ultraviolet A corneal collagen cross-linking for keratoconus in Italy: The Siena Eye Cross Study. Am J Ophthalmol 2010;149:4585-4593.

67. Wollensak G, Iomdina E. Biomechanical and histological changes after corneal crosslinking with and without epithelial debridement. J Cataract Refract Surg 2009;35:540-546.

68. Kymionis GD, Diakonis VF, Coskunseven E, et al. Customized pachymetric guided epithelial debridement for corneal collagen crosslinking. BMC Ophthalmol 2009;9:10-14.

69. Hafezi F, Mrochen M, Iseli HP, et al. Collagen crosslinking with ultraviolet-A and hypoosmolar riboflavin solution in thin corneas. J Cataract Refract Surg 2009;35:621-624.

70. Spadea L, Mencucci R. Transepithelial corneal collagen crosslinking in ultrathin keratoconic corneas. Clin Ophthalmol 2012;6:1785-1792.

71. Randleman JB. Post-laser in-situ keratomileusis ectasia: current understanding and future directions. Curr Opin Ophthalmol 2006; 17:406-412.

72. Dawson DG, Randleman JB, Grossniklaus HE, O'Brien TP, Dubovy SR, Schmack I, Stulting RD, Edelhauser HF. Corneal ectasia after excimer laser keratorefractive surgery: histopathology, ultrastructure, and pathophysiology. Ophthalmology 2008;115(12):2181-2191.

73. Jaycock PD, Lobo L, Ibrahim J, et al. Interferometric technique to measure biomechanical changes in the cornea induced by refractive surgery. J Cataract Refract Surg 2005;31:175-184.

74. Luce DA. Determining in vivo biomechanical properties of the cornea with an ocular response analyzer. J Cataract Refract Surg 2005;31:156-162.

75. Kymionis GD, Portaliou DM, Diakonis VF, et al. Management of post laser in situ keratomileusis ectasia with simultaneous topography guided photorefractive keratectomy and collagen cross-linking. Open Ophthalmol J 2011;5:11-13.

76. Kanellopoulos J, Binder P. Collagen crosslinking (CCL) with sequential topography-guided PRK. A temporizing alternative for keratoconus to penetrating keratoplasty. Cornea 2007;26:891-895. 
77. Mazzotta C, Traversi C, Baiocchi S, et al. Corneal healing after riboflavin ultraviolet-A collagen cross-linking determined by confocal laser scanning microscopy in vivo: early and late modifications. Am J Ophthalmol 2008;146(4):527-533.

78. Celik HU, Alagoz N, Yildirim Y, et al. Accelerated corneal crosslinking concurrent with laser in situ keratomileusis. J Cataract Refract Surg 2012;38:1424-1431 .

79. Kymionis GD, Bouzoukis DI, Diakonis VF, et al. Diffuse lamellar keratitis after corneal crosslinking in a patient with postlaser in situ keratomileusis corneal ectasia. J Cataract Refract Surg 2007;33:2135-2137.

80. Shah MN, Misra M, Wilhelmus KR, et al. Diffuse lamellar keratitis associated with epithelial defects after laser in situ keratomileusis. J Cataract Refract Surg 2000;26:1312-1318.

81. Kanellopoulos AJ. Long-term safety and efficacy follow-up of prophylactic higher fluence collagen cross-linking in high myopic laser-assisted in situ keratomileusis. Clin Ophthalmol 2012;6:1125-1130

82. Spadea L, Paroli M. Simultaneous topography-guided PRK followed by corneal collagen cross-linking after lamellar keratoplasty for keratoconus. Clin Ophthalmol 2012;6: 1793-1800.

\section{ABOUT THE AUTHORS}

\section{Leopoldo Spadea}

Associate Clinical Professor of Ophthalmology, Department of Medical-Surgical Sciences and Biotechnology, La Sapienza University of Rome, Latina, Italy

Correspondence Address: Via Benozzo Gozzoli 34, 00142 Rome Italy, Phone/Fax:+39065193220, e-mail: leopoldo.spadea@uniromal.it

\section{Francesca Verboschi}

Member in Training, Department of Medical-Surgical Sciences and Biotechnology, La Sapienza University of Rome, Latina, Italy

\section{Stefano Valente}

Member in Training, Department of Medical-Surgical Sciences and Biotechnology, La Sapienza University of Rome, Latina, Italy

\section{Enzo Maria Vingolo}

Aggregate Clinical Professor of Ophthalmology, Department of Medical-Surgical Sciences and Biotechnology, La Sapienza University of Rome, Latina, Italy 